\title{
Butyric acid production from lignocellulosic biomass hydrolysates by engineered Clostridium tyrobutyricum overexpressing xylose catabolism genes for glucose and xylose co-utilization
}

Hongxin $\mathrm{Fu}^{1,2}$ Shang-Tian Yang ${ }^{2, *} \quad$ Mingqi Wang $^{3} \quad$ Jufang Wang $^{1} \quad$ I-Ching Tang $^{4}$

${ }^{1}$ School of Bioscience and Bioengineering, South China University of Technology, Guangzhou 510006, China

${ }^{2}$ Department of Chemical and Biomolecular Engineering, The Ohio State University, 151 West Woodruff Avenue, Columbus, Ohio 43210, USA

${ }^{3}$ School of Animal Science and Technology, Zhejiang University, Hangzhou, Zhejiang, China ${ }^{4}$ Bioprocessing Innovative Company, 4734 Bridle Path Ct., Dublin, Ohio 43017, USA

*Corresponding author: Phone: 614-2926611; fax: 614-2923769; Email: yang.15@ osu.edu Submitted to Bioresource Technology 


\section{Abstract}

2 Clostridium tyrobutyricum can utilize glucose and xylose as carbon source for butyric acid

3 production. However, xylose catabolism is inhibited by glucose, hampering butyric acid

4 production from lignocellulosic biomass hydrolysates containing both glucose and xylose. In this

5 study, an engineered strain of $C$. tyrobutyricum Ct-pTBA overexpressing heterologous xylose

6 catabolism genes $(x y l T, x y l A$, and $x y l B)$ was investigated for co-utilizing glucose and xylose

7 present in hydrolysates of plant biomass, including soybean hull, corn fiber, wheat straw, rice

8 straw, and sugarcane bagasse. Compared to the wild-type strain, Ct-pTBA showed higher xylose

9 utilization without significant glucose catabolite repression, achieving near $100 \%$ utilization of

10 glucose and xylose present in lignocellulosic biomass hydrolysates in bioreactor at $\mathrm{pH}$ 6. About

$1142.6 \mathrm{~g} / \mathrm{L}$ butyrate at a productivity of $0.56 \mathrm{~g} / \mathrm{L} \cdot \mathrm{h}$ and yield of $0.35 \pm 0.02 \mathrm{~g} / \mathrm{g}$ was obtained in batch

12 fermentation, demonstrating the potential of $C$. tyrobutyricum Ct-pTBA for butyric acid

13 production from lignocellulosic biomass hydrolysates.

14 Keywords: Butyric acid; Clostridium tyrobutyricum; glucose carbon catabolite repression;

15 lignocellulosic biomass hydrolysates; xylose 


\section{1. Introduction}

Butyric acid, a specialty chemical widely used in food and pharmaceutical industries, is produced mainly from petroleum-based feedstocks via chemical synthesis (Dwidar et al., 2012; Zhang et al., 2009). However, the demand for bio-based products from renewable resources and concern over environmental pollution by chemical synthesis have revived the interest for butyric acid fermentation (Baumann and Westermann, 2016; Wang et al., 2016; Yang et al., 2013). To date, Clostridium tyrobutyricum has been studied extensively for butyric acid production from a variety of fermentable sugars and starch- and sucrose-based substrates including cane molasses (Jiang et al., 2009), wheat flour (Fayolle et al., 1990), Jerusalem artichoke (Huang et al., 2011), sweet sorghum, and beet molasses (Sjoblom et al., 2015), achieving a high final titer (55.2 to $62.8 \mathrm{~g} / \mathrm{L})$, yield $(0.38$ to $0.52 \mathrm{~g} / \mathrm{g})$, and productivity $(1.1$ to $3.2 \mathrm{~g} / \mathrm{L} \cdot \mathrm{h})$ in fed-batch fermentation. is limiting the industrial production of bio-based butyric acid.

However, the relatively high cost of these substrates, which account for $\sim 50 \%$ of the overall cost

$$
\text { More recently, attention has turned to using non-food feedstocks such as lignocellulosic }
$$
biomass including agricultural residues for economical and sustainable production of bio-based butyric acid (Baroi et al., 2015a; 2015b; Huang et al., 2016a; Lee et al., 2015a; Liu et al., 2013;

Wei et al., 2013; Zhu et al., 2002). However, there are several problems in using lignocellulosic biomass for fermentation, including difficulty in breaking down the recalcitrant plant biomass for cellulose hydrolysis, growth inhibition by the toxic compounds present in the hydrolysates, and low xylose utilization efficiency (Jönsson et al., 2013; Menon and Rao, 2012). Although many microorganisms, including C. tyrobutyricum, is able to utilize xylose as carbon source (Jiang et 
al., 2010; 2011; Liu and Yang, 2006; Zhu and Yang, 2004), xylose catabolism is usually inhibited by glucose (Baroi et al., 2015a), which is commonly referred as carbon catabolite repression

3 (CCR) (Görke and Stülke, 2008; Yao and Shimizu, 2013). Simultaneous utilization of glucose and xylose, two major sugars in lignocellulosic biomass hydrolysates, is the prerequisite for exploiting economically competitive and sustainable biological process for fuels and chemicals production (Gu et al., 2014; Ho et al., 1998; Liu et al., 2013; Wang et al., 2014; Wei et al., 2016).

$7 \quad$ Engineering cells to overexpress xylose catabolism genes $(x y l T, x y l A$ and $x y l B)$ could eliminate or alleviate the glucose-mediated CCR and thus enhance xylose utilization and butanol production by Clostridium (Gu et al., 2010; Xiao et al., 2011; Yu et al., 2015). Recently, we have also overexpressed $x y l T, x y l A$ and $x y l B$ in $C$. tyrobutyricum for butyric acid production from both glucose and xylose (Fu et al., 2017). The objective of the present study was to further evaluate and xylose for butyric acid production from lignocellulosic biomass. Batch fermentations with free cells in serum bottles containing hydrolysates of soybean hull, sugarcane bagasse, corn fiber, wheat straw, and rice straw were studied first, and the best two hydrolysates from soybean hull and sugarcane bagasse were further studied in bioreactor with $\mathrm{pH}$ controlled at 6.0. The results undetoxified hydrolysates, achieving the highest butyric acid titer of $42.6 \mathrm{~g} / \mathrm{L}$ ever reported in a free-cell fermentation using lignocellulosic biomass hydrolysate. This study demonstrated the potential of $C$. tyrobutyricum Ct-pTBA for bio-based butyric acid production. 


\section{Materials and methods}

\subsection{Cultures and media}

C. tyrobutyricum Ct-pTBA used in this study was obtained by transforming the strain ATCC 25755 with the plasmid pTBA for overexpressing three xylose catabolism genes $(x y l T, x y l A$, and $x y l B$ ) from $C$. acetobutylicum. The construction of Ct-pTBA followed similar procedures described elsewhere (Fu et al., 2017). Unless otherwise noted, the strain was cultured anaerobically at $37^{\circ} \mathrm{C}$ in Clostridial Growth Medium (CGM) (Liu et al., 2006a; Zhu et al., 2005) supplemented with $30 \mu \mathrm{g} / \mathrm{mL}$ thiamphenicol. The CGM contained (g/L): 50 glucose, 2 yeast extract, 4 tryptone, $2\left(\mathrm{NH}_{4}\right)_{2} \mathrm{SO}_{4}, 1 \mathrm{~K}_{2} \mathrm{HPO}_{4} \cdot 3 \mathrm{H}_{2} \mathrm{O}, 0.5 \mathrm{KH}_{2} \mathrm{PO}_{4}, 0.1 \mathrm{MgSO}_{4} \cdot 7 \mathrm{H}_{2} \mathrm{O}$, and trace minerals.

\subsection{Preparation of lignocellulosic biomass hydrolysates}

Lignocellulosic biomass, including soybean hull (yellow pellets), corn fiber (yellow pellets), wheat straw (brown particles), rice straw (yellow particles) and sugarcane bagasse (brown powder), was pretreated with dilute acid and then hydrolyzed to obtain hydrolysates containing fermentable sugars (glucose, xylose and arabinose). Briefly, biomass was mixed with dilute acid $\left(0.04 \mathrm{M} \mathrm{HCl}\right.$ or $\left.0.01-0.02 \mathrm{M} \mathrm{H}_{2} \mathrm{SO}_{4}\right)$ at a solid/liquid ratio of $10 \%(\mathrm{w} / \mathrm{v})$ and autoclaved at $121{ }^{\circ} \mathrm{C}$ for $30 \mathrm{~min}$. The acid and its concentration used in the pretreatment of a biomass were chosen for maximum sugar yield based on data from previous studies (Dong 2014; Du 2013; Lee et al., 2015a; Liu et al., 2013). After cooling and adjusting the $\mathrm{pH}$ to 5.0 with $\mathrm{NaOH}$, the pretreated biomass was treated with cellulases (Cellic ${ }^{\circledR}$ CTec $25.4 \%$ and HTec $20.6 \%$ w/w 
1 biomass, Novozymes North America, Inc., Franklinton, NC) for $72 \mathrm{~h}$ at $50^{\circ} \mathrm{C}$ and $150 \mathrm{rpm}$. After

2 removing insoluble solids by centrifugation at $8000 \mathrm{rpm}$ for $20 \mathrm{~min}$, the supernatant was

3 concentrated by evaporation to a desirable total sugar concentration of $\sim 40 \mathrm{~g} / \mathrm{L}$ and then stored at $4 \quad 4{ }^{\circ} \mathrm{C}$.

\subsection{Butyric acid fermentation}

Butyric acid production in batch fermentation was first studied in serum bottles $(50 \mathrm{~mL})$, with glucose, xylose, the mixture of glucose and xylose ( 1:1), and hydrolysates of various biomass, including soybean hull $(\mathrm{SHH})$, corn fiber $(\mathrm{CFH})$, wheat straw (WSH), rice straw (RSH), and sugarcane bagasse (SBH), respectively, as the carbon source and $40 \mathrm{~g} / \mathrm{L}$ calcium carbonate as buffer. The medium, which had an initial $\mathrm{pH}$ value of $\sim 6.5$, was autoclaved at $121^{\circ} \mathrm{C}$ for $30 \mathrm{~min}$, sparged with nitrogen for $\sim 30 \mathrm{~min}$, and then inoculated with an active seed culture $(\sim 24 \mathrm{~h})$ at a volume ratio of $5 \%$. Batch fermentation kinetics was then studied in 1-L stirred-tank bioreactors

$13(600 \mathrm{~mL})$ with selected hydrolysates and $\mathrm{pH}$ controlled at 6.0 with $30 \%(\mathrm{v} / \mathrm{v})$ ammonium hydroxide. Broth samples were taken periodically throughout the fermentation. All fermentation 15 conditions were studied in duplicate.

\subsection{Analytical methods}

17 Cell density was monitored by measuring the optical density (OD) at $600 \mathrm{~nm}$ using a spectrophotometer (UV-16-1, Shimadzu, Columbia, MD). Organic acids and sugars were

19 determined by HPLC (LC-20AD, Shimadzu, Columbia, MD) with an organic acid analysis column (HPX-87H, Bio-Rad, Hercules, CA) at $65{ }^{\circ} \mathrm{C}$ and $0.005 \mathrm{M}$ sulfuric acid at $0.6 \mathrm{~mL} / \mathrm{min}$ as 
the mobile phase following the previously described method (Liu et al., 2006b).

\section{$2 \quad 3$. Results and discussion}

3

4

5

6

\subsection{Effects of overexpressing xylose catabolism genes}

To evaluate the effects of overexpressing the xylose catabolism genes $x y l T, x y l A$, and $x y l B$ on $C$. tyrobutyricum growth and sugar metabolism, fermentation in CGM containing glucose, xylose, and glucose/xylose mixture, respectively, as carbon source was studied with Ct-pTBA and its parental strain (wild type $\mathrm{Ct}$ without pTBA). Figure 1 shows the fermentation kinetics with $\mathrm{Ct}$ and Ct-pTBA cultured in serum bottles. It is noted that the fermentation stopped before all substrate was consumed because the culture $\mathrm{pH}$ had dropped from the initial $\sim 6.5$ to below 5.0 due to acids production. Compared to glucose, xylose utilization was more sensitive to the $\mathrm{pH}$ and was inhibited at acidic $\mathrm{pH}$. Ct-pTBA was able to use xylose at a faster rate either with or without the presence of glucose. In fact, the wild type strain $\mathrm{Ct}$ was not able to use xylose in the presence of glucose due to glucose-induced CCR. Clearly, overexpressing $x y l T, x y l A$, and $x y l B$ alleviated glucose repression and afforded Ct-pTBA the ability to use glucose and xylose simultaneously, although glucose as the preferred substrate was consumed at a faster rate than xylose. Compared to the wild-type, Ct-pTBA grew slower on glucose, probably because of the additional metabolic burden imposed by the constitutive expression of heterologous genes not required for growth with glucose as the sole carbon source.

\subsection{Butyric acid fermentation with hydrolysates in serum bottles}

Figure 2 shows the fermentation kinetics of Ct-pTBA utilizing sugars (glucose, xylose, and 
arabinose) present in various biomass hydrolysates ( $\mathrm{SHH}, \mathrm{CFH}, \mathrm{WSH}, \mathrm{RSH}$ and $\mathrm{SBH}$ ) in serum bottles. As expected, glucose and xylose were consumed simultaneously in these fermentations.

3 However, xylose consumption was much slower compared to glucose, especially when the $\mathrm{pH}$

4 was allowed to decrease to lower than 6.0 (Fig. 2A-E). Except for RSH, almost all glucose in

5 the hydrolysates was consumed in $72 \mathrm{~h}$, whereas only $27 \%-52 \%$ of xylose was consumed in

$6 \quad 120 \mathrm{~h}$ when the fermentation stopped due to low $\mathrm{pH}$. About $10.6-14.4 \mathrm{~g} / \mathrm{L}$ butyrate was

7 produced with a yield of $0.37-0.40 \mathrm{~g} / \mathrm{g}$ sugar consumed in these fermentations. With daily $\mathrm{pH}$

8 adjustment to 6.0 (Fig. 2F-J), xylose utilization increased to 65\%-94\%, resulting in a

$9 \quad$ significantly higher final butyrate titer $(12.3-15.3 \mathrm{~g} / \mathrm{L})$ and productivity $(0.15 \pm 0.01 \mathrm{~g} / \mathrm{L} \cdot \mathrm{h}$ vs. $0.12 \pm 0.01 \mathrm{~g} / \mathrm{L} \cdot \mathrm{h})$. For $\mathrm{CFH}, \mathrm{WSH}, \mathrm{SHH}$ and $\mathrm{SBH}$, the increased xylose utilization rate was at the expense of decreased glucose consumption rate. Clearly, both glucose and xylose catabolisms were inhibited by acidic pHs, but the inhibition was more pronounced on xylose.

13 The higher $\mathrm{pH}$ sensitivity for xylose catabolism could be attributed to that xylose transport is

14 mainly through the xylose-proton symporter while glucose is via the phosphoenolpyruvate

15 (PEP)-dependent glucose phosphotransferase system (PTS). It should be mentioned that cell

16 growth and fermentation were inhibited by the undissociated acids (Tang et al., 1989),

17 especially butyric acid (Wu and Yang, 2003), which with a $p K_{a}$ value of 4.82 dominated at $\mathrm{pH}$

$18<5.0$. The cytotoxicity of the undissociated butyric acid can be attributed to its impacts on the

19 transmembrane $\mathrm{pH}$ gradient, ATP generation, and activities of acid-forming enzymes (Zhu and

20 Yang, 2003). Our result was consistent with a previous study showing 50\% reduction in the

21 xylose consumption rate at $\mathrm{pH} 5.3$ as compared to at $\mathrm{pH} 6.3$ in batch fermentations by $C$. 
tyrobutyricum (Zhu and Yang, 2004).

Table 2 summarizes the fermentation results with the five hydrolysates studied. Among them, RSH gave the lowest butyrate productivity, probably because of the high ash content (10-17\%; of which $\sim 75 \%$ was $\mathrm{SiO}_{2}$ ) in rice straw, which is known to inhibit fermentation (Binnod et al., 2010; Liu et al., 2013). The fermentation could also be inhibited by the phenolic compounds present in RSH (Lee et al., 2015a; 2015b). SHH gave the highest butyrate yield of $0.43 \mathrm{~g} / \mathrm{g}$ sugar consumed. The higher butyrate yield could be attributed to the protein present in SHH, which can also be used for butyrate production by $C$. tyrobutyricum (Sjoblom et al., 2015). The higher butyrate yield could also be attributed to the re-utilization of acetate $(\sim 2 \mathrm{~g} / \mathrm{L})$ in the fermentation. C. tyrobutyricum produces butyrate from butyryl-CoA through a CoA-transferase, which transfers CoA to acetate, allowing its reassimilation in the metabolic pathway (Lee et al., 2016).

Adding acetate in the medium thus could induce acetate reassimilation and increase butyrate yield (Jaros et al., 2012; Fu et al., 2017). The utilization of acetate present in the biomass hydrolysates during butyrate fermentation has also been reported for wheat straw (Baroi et al., 2015a), cane molasses (Jiang et al., 2009), sweet sorghum stalk (Sjoblom et al., 2015), and Japanese larch (Kim et al., 2016).

\subsection{Butyric acid fermentation in bioreactor at pH 6}

The serum bottle fermentation results suggested that $\mathrm{pH}$ control at $\sim 6.0$ would be crucial for efficient co-utilization of glucose and xylose by C. tyrobutyricum Ct-pTBA. Butyric acid fermentation of glucose and xylose with Ct-pTBA was thus further studied in a stirred-tank 
bioreactor with its $\mathrm{pH}$ controlled at 6.0 (Fig. 3A). At pH 6, glucose and xylose were consumed simultaneously at a similar consumption rate of $1.05 \pm 0.05 \mathrm{~g} / \mathrm{L} \cdot \mathrm{h}$ in the fermentation and $37.5 \mathrm{~g} / \mathrm{L}$ butyrate was produced at a productivity of $0.72 \mathrm{~g} / \mathrm{L} \cdot \mathrm{h}$ and yield of $0.34 \mathrm{~g} / \mathrm{g}$. Clearly, both sugar consumption and butyrate productivity improved significantly with the $\mathrm{pH}$ controlled at 6.0 as comparison with the results from glucose/xylose mixture, we supplemented SHH and SBH with additional xylose to make the initial glucose/xylose ratio close to 1 . After a long lag phase of $\sim 80$ $\mathrm{h}$, both glucose and xylose in the concentrated hydrolysates were used simultaneously by acetate in the fermentation with glucose/xylose (Table 3). Clearly, the carbon flux shifted to 
containing a relatively high amount of acetate, which inhibited acetate production and facilitated the butyrate biosynthesis reaction catalyzed by CoA transferase (Fu et al., 2017; Lee et al., 2016). However, the total carbon accounted by butyrate and acetate was similar $(\sim 53 \%$ of the total substrate carbon) for all three fermentations.

It is noted that a higher cell density, as indicated by the $\mathrm{OD}_{600}$ value, was also reached in the fermentations with $\mathrm{SHH}$ and $\mathrm{SBH}$, probably because these hydrolysates contained additional nitrogen sources for cell growth. However, both the specific growth rate $\left(0.055-0.086 \mathrm{~h}^{-1} \mathrm{vs}\right.$. $\left.0.142 \mathrm{~h}^{-1}\right)$ and butyrate productivity $(0.56-0.67 \mathrm{~g} / \mathrm{L} \cdot \mathrm{h}$ vs. $0.72 \mathrm{~g} / \mathrm{L} \cdot \mathrm{h})$ were significantly lower with the concentrated hydrolysates, which might contain weak acids, furan derivatives and phenolic compounds toxic to cells (Cheng et al., 2008; Ezeji et al., 2007; Liu et al., 2013; Zhang et al., 2016). The type and amount of inhibitors present in the hydrolysate determine its toxicity and are dependent on the feedstock and pretreatment method used (Jönsson et al., 2013). In general, a mild pretreatment method applied to a less recalcitrant feedstock would generate fewer inhibitors in the hydrolysate. It has been reported that the hydrolysates obtained from dilute acid pretreated lignocellulosic biomass, including corn stover (Liu et al., 2013), rice straw (Lee et al., 2015a), and wheat straw (Baroi et al., 2015a) were highly toxic to $C$. tyrobutyricum, resulting in poor cell growth and little butyrate production. Nevertheless, butyric acid production could be improved significantly after detoxification of the hydrolysates (Jönsson et al., 2013; Lee et al., 2015a; 2015b) and adaptation of cells to better tolerate the inhibitors (Baroi et al., 2015a).

\subsection{Comparison to other studies}


Butyric acid fermentation with glucose or fermentable sugars as carbon source can achieve

high final product titer $(>60 \mathrm{~g} / \mathrm{L})$, yield $(>0.46 \mathrm{~g} / \mathrm{g})$ and productivity $(>2 \mathrm{~g} / \mathrm{L} \cdot \mathrm{h})$ (Yang et al., 2013). On the other hand, similar fermentations using hydrolysates of lignocellulosic biomass such as wheat straw, corn stover, corn fiber, rice hull, and switchgrass usually gave poor performance, including inefficient xylose utilization and low productivity (see Table 4). In our study, we showed that Ct-pTBA overexpressing xylose catabolism genes was able to co-utilize glucose and xylose in un-detoxified hydrolysates, such as $\mathrm{SHH}$ and $\mathrm{SBH}$, for butyric acid production, achieving a high final butyric acid concentration of $29.7-42.6 \mathrm{~g} / \mathrm{L}$, which was much higher than those previously reported with similar biomass hydrolysates in a free-cell fermentation (9-20 g/L) or even some immobilized-cell fermentations (Wei et al., 2013; Zhu et al., 2002) (see Table 4).

However, it should be mentioned that butyric acid fermentation can be improved by immobilizing cells in a bioreactor, such as the fibrous bed bioreactor (FBB), which can increase cell density and tolerance to butyric acid and hydrolysate inhibitors, and thus greatly increase final butyrate titer and productivity (Jiang et al., 2011; Huang et al., 2016a; 2016b; Zhu and Yang, 2003). Interestingly, cell immobilization in the FBB also facilitated the co-utilization of glucose and xylose by $C$. tyrobutyricum ATCC 25755 (Wei et al., 2013; Zhu et al., 2002). In addition, butyric acid production can also be improved by in situ removal of the inhibiting butyric acid from the fermentation broth (Baroi et al., 2015b; Wu and Yang, 2003). These approaches should also be implemented in future industrial production of butyric acid from lignocellulosic biomass such as sugarcane bagasse, the most abundant industrial waste (280 kg bagasse/ton sugarcane) 
1 from alcohol and sugar industries (Cardona et al., 2010) and soybean hull, the major byproduct

2 of the soybean processing (accounting for $\sim 8 \%$ of the whole seed) with an annual output of 17.3

3 million tons (Schirmer-Michel et al., 2008).

\section{4. Conclusions}

5 C. tyrobutyricum Ct-pTBA overexpressing heterologous xylose catabolism genes ( $x y l T, x y l A$,

6 and $x y l B$ ) showed excellent ability to co-ferment glucose and xylose present in undetoxified

7 lignocellulosic biomass hydrolysates for butyric acid production, achieving a high product titer,

8 yield, and productivity. The fermentation can be further improved with cell adaptation and

9 process optimization, providing a sustainable process for cost-effective production of butyric

10 acid from abundant lignocellulosic biomass.

\section{Acknowledgements}

12 This work was supported in part by the National Science Foundation STTR program

13 (IIP-1026648) and the Ministry of Agriculture 948 project (No. 2014-Z27), China. 


\section{References}

1. Baroi, G. N., Baumann, I., Westermann, P., Gavala, H. N., 2015a. Butyric acid fermentation from pretreated and hydrolysed wheat straw by an adapted Clostridium tyrobutyricum strain. Microb. Biotechnol. 8, 874-882.

2. Baroi, G. N., Skiadas, I. V., Westermann, P., Gavala, H. N., 2015b. Continuous fermentation of wheat straw hydrolysate by Clostridium tyrobutyricum with in-situ acids removal. Waste. Biomass. Valori. 6, 317-326.

3. Baumann, I., Westermann, P., 2016. Microbial production of short chain fatty acids from lignocellulosic biomass: Current processes and market. Biomed. Res. Int. 2016, Article ID 8469357; doi: 10.1155/2016/8469357

4. Binod, P., Sindhu, R., Singhania, R., Vikram, S., Devi, L., Nagalakshmi, S., Kurien, N., Sukumaran, K. R., Pandey, A., 2010. Bioethanol production from rice straw: An overview. Bioresour. Technol. 101, 4767-4774.

5. Cardona, C. A., Quintero, J. A., Paz, I. C., 2010. Production of bioethanol from sugarcane bagasse: Status and perspectives. Bioresour. Technol. 101, 4754-4766.

6. Cheng, K. K., Cai, B. Y., Zhang, J. A., Ling, H. Z., Zhou, Y. H., Ge, J. P., Xu, J. M., 2008. Sugarcane bagasse hemicellulose hydrolysate for ethanol production by acid recovery process. Biochem. Eng. J. 38, 105-109.

7. Dong, J., 2014. Butanol production from lignocellulosic biomass and agriculture residues by Acetone-Butanol-Ethanol fermentation. Ph.D. dissertation, The Ohio State University, Columbus, Ohio.

8. Du, Y., 2013. High-yield and high-titer n-butanol production from lignocellulosic feedstocks by metabolically engineered Clostridium tyrobutyricum, Ph.D. dissertation, The Ohio State University, Columbus, Ohio.

9. Dwidar, M., Park, J. Y., Mitchell, R. J., Sang, B. I., 2012. The future of butyric acid in industry. Sci. World. J. 2012, 471417.

10. Ezeji, T., Qureshi, N., Blaschek, H. P., 2007. Butanol production from agricultural residues: 
impact of degradation products on Clostridium beijerinckii growth and butanol fermentation. Biotechnol. Bioeng. 97, 1460-1469.

11. Fayolle, F., Marchal, R., Ballerini, D., 1990. Effect of controlled substrate feeding on butyric acid production by Clostridium tyrobutyricum. J. Ind. Microbiol. 6, 179-183.

12. Fu, H., Yu, L., Lin, M., Wang, J., Xiu, Z., Yang, S. T., 2017. Metabolic engineering of Clostridium tyrobutyricum for enhanced butyric acid production from glucose and xylose, Metab. Eng. in press. http://dx.doi.org/10.1016/j.ymben.2016.12.014

13. Görke, B., Stülke, J., 2008. Carbon catabolite repression in bacteria: many ways to make the most out of nutrients. Nat. Rev. Microbiol. 6, 613-624.

14. Gu, Y., Jiang, Y., Yang, S., Jiang, W. H., 2014. Utilization of economical substrate-derived carbohydrates by solventogenic clostridia: pathway dissection, regulation and engineering. Curr. Opin. Biotechnol. 29, 124-131.

15. Ho, N. W. Y., Chen, Z. D., Brainard, A. P., 1998. Genetically engineered Saccharomyces yeast capable of effective cofermentation of glucose and xylose. Appl. Environ. Microb. 64, 1852-1859

16. Huang, J., Cai, J., Wang, J., Zhu, X. C., Huang, L., Yang, S. T., Xu, Z. N., 2011. Efficient production of butyric acid from Jerusalem artichoke by immobilized Clostridium tyrobutyricum in a fibrous-bed bioreactor. Bioresource. Technol. 102, 3923-3926.

17. Huang, J., Zhu, H., Tang, W., Wang, P., Yang, S.T. 2016a. Butyric acid production from oilseed rape straw by Clostridium tyrobutyricum immobilized in a fibrous bed bioreactor. Process. Biochem., 51, 1930-1934.

18. Huang, J. Dai, H.L. Yan, R. Wang, P. 2016b. Butyric acid production from recycled waste paper by immobilized Clostridium tyrobutyricum in a fibrous-bedbioreactor, J. Chem. Technol. Biotechnol. 91, 1048-1054.

19. Jaros, A., Rova, U., Berglund, K.A. 2012. Effect of acetate on fermentation production of butyrate. Cell. Chem. Technol, 46, 341-347

20. Jiang, L., Wang, J. F., Liang, S. Z., Wang, X. N., Cen, P. L., Xu, Z. N., 2009. Butyric acid fermentation in a fibrous bed bioreactor with immobilized Clostridium tyrobutyricum from cane 
molasses. Bioresource. Technol. 100, 3403-3409.

21. Jiang, L., Wang, J. F., Liang, S. Z., Wang, X. N., Cen, P. L., Xu, Z. N., 2010. Production of butyric acid from glucose and xylose with immobilized cells of Clostridium tyrobutyricum in a fibrous-bed bioreactor. Appl. Biochem. Biotech. 160, 350-359.

22. Jiang, L., Wang, J. F., Liang, S. Z., Cai, J., Xu, Z. N., Cen, P. L., Yang, S. T., Li, S. A., 2011. Enhanced butyric acid tolerance and bioproduction by Clostridium tyrobutyricum immobilized in a fibrous bed bioreactor. Biotechnol. Bioeng. 108, 31-40.

23. Jönsson, L.J., Alriksson, B., Nilvebrant, N.-O. 2013. Bioconversion of lignocellulose: inhibitors and detoxification. Biotechnol. Biofuels. 6, 1.

24. Kim, M., Kim, K. Y., Lee, K. M., Youn, S. H., Lee, S. M., Han, M. W., Oh, M. K., Um, Y., 2016. Butyric acid production from softwood hydrolysate by acetate-consuming Clostridium sp. S1 with high butyric acid yield and selectivity. Bioresour. Technol. 218, 1208-1214.

25. Lee, K. M., Kim, K. Y., Choi, O., Woo, H. M., Kim, Y., Han, S. O., Sang, B. I., Um, Y., 2015a. In situ detoxification of lignocellulosic hydrolysate using a surfactant for butyric acid production by Clostridium tyrobutyricum ATCC 25755. Process Biochem. 50, 630-635.

26. Lee, K. M., Min, K., Choi, O., Kim, K. Y., Han, M. W., Kim, Y., Han, S. O., Um, Y., $2015 b$. Electrochemical detoxification of phenolic compounds in lignocellulosic hydrolysate for Clostridium fermentation. Bioresour. Technol. 187, 228-234.

27. Lee, J., Jang, Y. S., Han, M. J., Kim, J. Y., Lee, S. Y., 2016. Deciphering Clostridium tyrobutyricum metabolism based on the whole-genome sequence and proteome analyses. $\mathrm{mBio}$ 7(3), e00743-16.

28. Liu, S.Q., Bischoff, K. M., Leathers, T. D., Qureshi, N., Rich, J. O., Hughes, S. R., 2013. Butyric acid from anaerobic fermentation of lignocellulosic biomass hydrolysates by Clostridium tyrobutyricum strain RPT-4213. Bioresour. Technol. 143, 322-329.

29. Liu, X., Yang, S. T., 2006. Kinetics of butyric acid fermentation of glucose and xylose by Clostridium tyrobutyricum wild type and mutant, Process Biochem. 41, 801-808.

30. Liu, X., Zhu, Y., Yang, S. T., 2006a. Construction and characterization of ack deleted mutant of 
Clostridium tyrobutyricum for enhanced butyric acid and hydrogen production. Biotechnol. Progr. $22,1265-1275$.

31. Liu, X., Zhu, Y., Yang, S. T., 2006b. Butyric acid and hydrogen production by Clostridium tyrobutyricum ATCC 25755 and mutants, Enz. Microb. Technol. 38, 521-528.

32. Menon, V., Rao, M., 2012. Trends in bioconversion of lignocellulose: Biofuels, platform chemicals \& biorefinery concept. Prog. Energ. Combust. 38, 522-550.

33. Schirmer-Michel, Â. C., Flôres, S. H., Hertz, P. F., Matos, G. S., Ayub, M. A. Z., 2008. Production of ethanol from soybean hull hydrolysate by osmotolerant Candida guilliermondii NRRL Y-2075. Bioresour. Technol. 99, 2898-2904.

34. Sjoblom, M., Matsakas, L., Christakopoulos, P., Rova, U., 2015. Production of butyric acid by Clostridium tyrobutyricum (ATCC 25755) using sweet sorghum stalks and beet molasses. Ind. Crop. Prod. 74, 535-544.

35. Tang, I. C., Okos, M. R., Yang, S. T., 1989. Effects of pH and acetic acid on homoacetic fermentation of lactate by Clostridium formicoaceticum, Biotechnol. Bioeng. 34, 1063-1074.

36. Wang, J. F., Yang, X. R., Chen, C. C., Yang, S. T., 2014. Engineering clostridia for butanol production from biorenewable resources: from cells to process integration. Curr. Opin. Chem. Eng. 6, 43-54.

37. Wang, J. F., Lin, M., Xu, M. M., Yang, S. T., 2016. Anaerobic fermentation for production of carboxylic acids as bulk chemicals from renewable biomass. Adv. Biochem. Eng. Biotechnol. 156, $323-361$.

38. Wei, D., Liu, X. G., Yang, S. T., 2013. Butyric acid production from sugarcane bagasse hydrolysate by Clostridium tyrobutyricum immobilized in a fibrous-bed bioreactor. Bioresour. Technol. 129, 553-560.

39. Wei, P., Lin, M., Wang, Z., Fu, H., Yang, H., Jiang, W., Yang, S.T., 2016. Metabolic engineering of Propionibacterium freudenreichii subsp. shermanii for xylose fermentation, Bioresour. Technol., 219, 91-97.

40. Wu, Z., Yang, S. T., 2003. Extractive fermentation for butyric acid production from glucose by 
Clostridium tyrobutyricum, Biotechnol. Bioeng., 82, 93-102.

41. Xiao, H., Gu, Y., Ning, Y., Yang, Y., Mitchell, W. J., Jiang, W., Yang, S., 2011. Confirmation and elimination of xylose metabolism bottlenecks in glucose phosphoenolpyruvate-dependent phosphotransferase system-deficient Clostridium acetobutylicum for simultaneous utilization of glucose, xylose, and arabinose. Appl. Environ. Microb. 77, 7886-95.

42. Yang, S. T., Yu, M., Chang, W. L, Tang, I. C., 2013. Anaerobic fermentations for the production of acetic and butyric acids, in Yang, S. T., Elnshasy, H. A., Thongchul, N. (eds) Bioprocessing Technologies in Biorefinery for Sustainable Production of Fuels, Chemicals, and Polymers, Wiley: Hoboken, NJ, 351-373.

43. Yao, R., Shimizu, K., 2013. Recent progress in metabolic engineering for the production of biofuels and biochemicals from renewable sources with particular emphasis on catabolite regulation and its modulation. Process. Biochem. 48, 1409-1417.

44. Yu, L., Xu, M. M., Tang, I. C., Yang, S. T., 2015. Metabolic engineering of Clostridium tyrobutyricum for n-butanol production through co-utilization of glucose and xylose. Biotechnol. Bioeng. 112, 2134-2141.

45. Zhang, C. H., Yang, H., Yang, F. X., Ma, Y. J., 2009. Current progress on butyric acid production by fermentation. Curr. Microbiol. 59, 656-663.

46. Zhang, L., Li, X., Yong, Q., Yang, S. T., Ouyang, J., Yu, S., 2016. Impacts of lignocellulose-derived inhibitors on L-lactic acid fermentation by Rhizopus oryzae, Bioresourc. Technol., 203, 173-180.

47. Zhu, Y., Yang, S. T., 2003. Adaptation of Clostridium tyrobutyricum for enhanced tolerance to butyric acid in a fibrous-bed bioreactor, Biotechnol. Progress 19, 365-372.

48. Zhu, Y., Yang, S. T., 2004. Effect of $\mathrm{pH}$ on metabolic pathway shift in butyric acid fermentation by Clostridium tyrobutyricum, J. Biotechnol. 110, 143-157.

49. Zhu, Y., Wu, Z. T., Yang, S. T., 2002. Butyric acid production from acid hydrolysate of corn fibre by Clostridium tyrobutyricum in a fibrous-bed bioreactor. Process. Biochem. 38, 657-666.

50. Zhu, Y., Liu, X. G., Yang, S. T., 2005. Construction and characterization of pta gene-deleted 
mutant of Clostridium tyrobutyricum for enhanced butyric acid fermentation. Biotechnol. Bioeng. 90, 154-166. 
Table 1. Compositions of various lignocellulosic biomass hydrolysates obtained after acid pretreatment, enzymatic hydrolysis, and concentration.

\begin{tabular}{llccccc}
\hline Biomass & $\begin{array}{l}\text { Pretreatment* } \\
\text { acid }\end{array}$ & $\begin{array}{c}\text { Glucose } \\
(\mathrm{g} / \mathrm{L})\end{array}$ & $\begin{array}{c}\text { Xylose } \\
(\mathrm{g} / \mathrm{L})\end{array}$ & $\begin{array}{c}\text { Arabinose } \\
(\mathrm{g} / \mathrm{L})\end{array}$ & $\begin{array}{c}\text { Total sugar } \\
(\mathrm{g} / \mathrm{L})\end{array}$ & $\begin{array}{c}\text { Acetate } \\
(\mathrm{g} / \mathrm{L})\end{array}$ \\
\hline Soybean hull & $0.04 \mathrm{M} \mathrm{HCl}$ & 31.50 & 12.69 & 0.01 & 44.20 & 1.99 \\
Corn fiber & $0.01 \mathrm{M} \mathrm{H}_{2} \mathrm{SO}_{4}$ & 37.45 & 6.62 & 5.67 & 49.74 & 0.54 \\
Wheat straw & $0.02 \mathrm{M} \mathrm{H}_{2} \mathrm{SO}_{4}$ & 33.60 & 11.03 & 2.19 & 46.82 & 0.90 \\
Rice straw & $0.02 \mathrm{M} \mathrm{H}_{2} \mathrm{SO}_{4}$ & 31.03 & 5.89 & 0.63 & 37.55 & 0.21 \\
Sugarcane bagasse & $0.04 \mathrm{M} \mathrm{HCl}^{2}$ & 24.75 & 17.10 & 1.28 & 43.13 & 1.60 \\
\hline
\end{tabular}

*The type of inorganic acid and concentration were chosen for maximum sugar yield based on data from previous studies (Dong 2014; Du 2013; Lee et al., 2015a; Liu et al., 2013). 
Table 2. Butyrate production from various biomass hydrolysates by $C$. tyrobutyricum Ct-pTBA in serum bottles with and without daily adjustment of $\mathrm{pH}$ to 6.0 .

\begin{tabular}{|c|c|c|c|c|c|c|c|c|}
\hline \multirow{2}{*}{ Substrate } & \multicolumn{2}{|c|}{ Xylose consumed (\%) } & \multicolumn{2}{|c|}{ Butyrate titer (g/L) } & \multicolumn{2}{|c|}{ Butyrate yield (g/g) } & \multicolumn{2}{|c|}{ Butyrate productivity $(\mathrm{g} / \mathrm{L} \cdot \mathrm{h})$} \\
\hline & Without & With & Without & With & Without & With & Without & With \\
\hline Soybean hull & $30.6 \pm 0.6$ & $73.6 \pm 0.9$ & $12.33 \pm 0.23$ & $15.34 \pm 0.03$ & $0.38 \pm 0.01$ & $0.43 \pm 0.01$ & $0.13 \pm 0.01$ & $0.15 \pm 0.01$ \\
\hline Corn fiber & $36.9 \pm 0.4$ & $70.5 \pm 0.7$ & $14.38 \pm 0.11$ & $13.95 \pm 0.37$ & $0.37 \pm 0.01$ & $0.37 \pm 0.01$ & $0.12 \pm 0.01$ & $0.14 \pm 0.00$ \\
\hline Wheat straw & $35.3 \pm 0.9$ & $84.4 \pm 0.6$ & $14.10 \pm 0.35$ & $15.18 \pm 0.18$ & $0.38 \pm 0.01$ & $0.40 \pm 0.01$ & $0.11 \pm 0.01$ & $0.15 \pm 0.01$ \\
\hline Rice straw & $52.0 \pm 0.9$ & $64.8 \pm 0.6$ & $6.40 \pm 0.12$ & $12.30 \pm 0.01$ & $0.40 \pm 0.01$ & $0.41 \pm 0.01$ & $0.05 \pm 0.01$ & $0.09 \pm 0.01$ \\
\hline Sugarcane bagasse & $27.0 \pm 0.8$ & $93.5 \pm 0.7$ & $10.55 \pm 0.28$ & $15.21 \pm 0.07$ & $0.38 \pm 0.01$ & $0.40 \pm 0.01$ & $0.11 \pm 0.01$ & $0.16 \pm 0.01$ \\
\hline
\end{tabular}


Table 3. Carbon balance in batch fermentations by Ct-pTBA with glucose/xylose, SHH, and $\mathrm{SBH}$ as carbon sources, respectively.

\begin{tabular}{llll}
\hline & Glucose/xylose & SHH & SBH \\
\hline Substrates & & & \\
Glucose & 1.89 & 1.46 & 2.00 \\
Xylose & 1.83 & 1.34 & 1.96 \\
Total & 3.72 & 2.80 & 3.96 \\
Products & & & \\
Acetic acid & $0.27(7.2 \%)$ & $0.18(6.4 \%)$ & $0.13(3.3 \%)$ \\
Butyric acid & $1.71(46.0 \%)$ & $1.35(48.2 \%)$ & $1.94(49.0 \%)$ \\
Total & $1.98(53.2 \%)$ & $1.53(54.6 \%)$ & $2.07(52.3 \%)$ \\
\hline
\end{tabular}

Values are given in C-mol. Values in parentheses are percentages of substrate carbon recovered in the products. SHH: soybean hull hydrolysate; $\mathrm{SBH}$ : sugarcane bagasse hydrolysate. 
Table 4. Butyrate production from various biomass hydrolysates by $C$. tyrobutyricum in fermentation

\begin{tabular}{|c|c|c|c|c|c|c|c|}
\hline Strain & Substrate & $\begin{array}{l}\text { Fermentation } \\
\text { Condition }\end{array}$ & $\begin{array}{l}\text { Xylose } \\
\text { utilization }\end{array}$ & $\begin{array}{l}\text { Titer } \\
(\mathrm{g} / \mathrm{L})\end{array}$ & $\begin{array}{l}\text { Yield } \\
(\mathrm{g} / \mathrm{g})\end{array}$ & $\begin{array}{l}\text { Productivity } \\
(\mathrm{g} / \mathrm{L} \cdot \mathbf{h})\end{array}$ & Reference \\
\hline \multirow[t]{3}{*}{ Ct-pTBA } & Glucose/Xylose & Batch, pH 6 & Yes, $95 \%$ & 37.5 & 0.34 & 0.72 & This study \\
\hline & Soybean hull & & Yes, $90 \%$ & 29.7 & 0.35 & $0.67 *$ & \\
\hline & Sugarcane bagasse & & Yes, $97 \%$ & 42.6 & 0.36 & $0.56^{*}$ & \\
\hline \multirow[t]{2}{*}{ RPT-4213 } & Wheat straw & Batch, pH 6 & NR & 9.87 & 0.44 & 0.41 & Liu et al., 2013 \\
\hline & Switchgrass & & NR & 7.05 & 0.42 & 0.29 & \\
\hline C. sp. S1 & Soft wood & Batch, pH 6 & Repressed & 21.2 & 0.47 & 0.66 & Kim et al., 2016 \\
\hline DSMZ 2637 & Wheat straw & Batch, pH 7 & Low, $20 \%$ & 20 & 0.33 & 0.21 & Baroi et al., 2015a \\
\hline ATCC 25755 & Rice straw & Batch & Low, $17 \%$ & 8.7 & 0.40 & 0.18 & Lee et al., 2015a \\
\hline ATCC 25755 & Sugarcane bagasse & FBB, fed-batch & Yes, $\sim 80 \%$ & 20.9 & 0.48 & 0.51 & Wei et al., 2013 \\
\hline ATCC 25755 & Corn fibre + CSL & FBB, batch & Yes, $82 \%$ & 29.0 & 0.47 & $2.91^{+}$ & Zhu et al., 2002 \\
\hline ZJU 8235 & Oilseed rape straw & FBB, fed-batch & NR & 50.2 & 0.38 & $1.08^{+}$ & Huang et al., 2016a \\
\hline ZJU 8235 & Waste paper & FBB, fed-batch & Yes, $\sim 80 \%$ & 53.4 & 0.40 & $1.33^{+}$ & Huang et al., 2016b \\
\hline
\end{tabular}

CSL: Corn steep liquor; FBB: Fibrous bed bioreactor; NR: Not reported

*Based on the exponential phase data; ${ }^{+}$Based on the FBB volume 


\section{$1 \quad$ List of Figures}

2 Figure 1. Batch fermentations of C. tyrobutyricum wild-type $(\mathrm{Ct})$ and mutant (Ct-pTBA)

3 overexpressing xylose-catabolism genes $x y l T, x y l B, x y l A$ in CGM with glucose, xylose

4 and glucose/xylose mixture (1:1) as substrates in serum bottles. Each fermentation

5 condition was repeated at least twice and typical fermentation kinetics is shown here.

6 Figure 2. Batch fermentations of Ct-pTBA grown in CGM with hydrolysates of soybean

7 hull $(\mathrm{SHH})$, corn fiber $(\mathrm{CFH})$, wheat straw (WSH), rice straw (RSH) and sugarcane

8 bagasse $(\mathrm{SBH})$, respectively, as substrates in serum bottles. (A-E) with $40 \mathrm{~g} / \mathrm{L}$ calcium

9 carbonate as buffer to maintain the $\mathrm{pH}$ above 5.0. (F-J) with the $\mathrm{pH}$ adjusted to 6.0 with

$10 \mathrm{NaOH}$ daily. The initial arabinose concentration was low $(<1 \mathrm{~g} / \mathrm{L})$ in $\mathrm{SHH}, \mathrm{RSH}$ and $\mathrm{SBH}$,

11 and is thus not shown in the figure. Each fermentation condition was repeated at least

12 twice and typical fermentation kinetics is shown here.

13 Figure 3. Batch fermentations of Ct-pTBA grown in CGM with glucose/xylose mixture

14 (A), SHH (B), and SBH (C), respectively, as substrates in bioreactor at pH 6.0. 

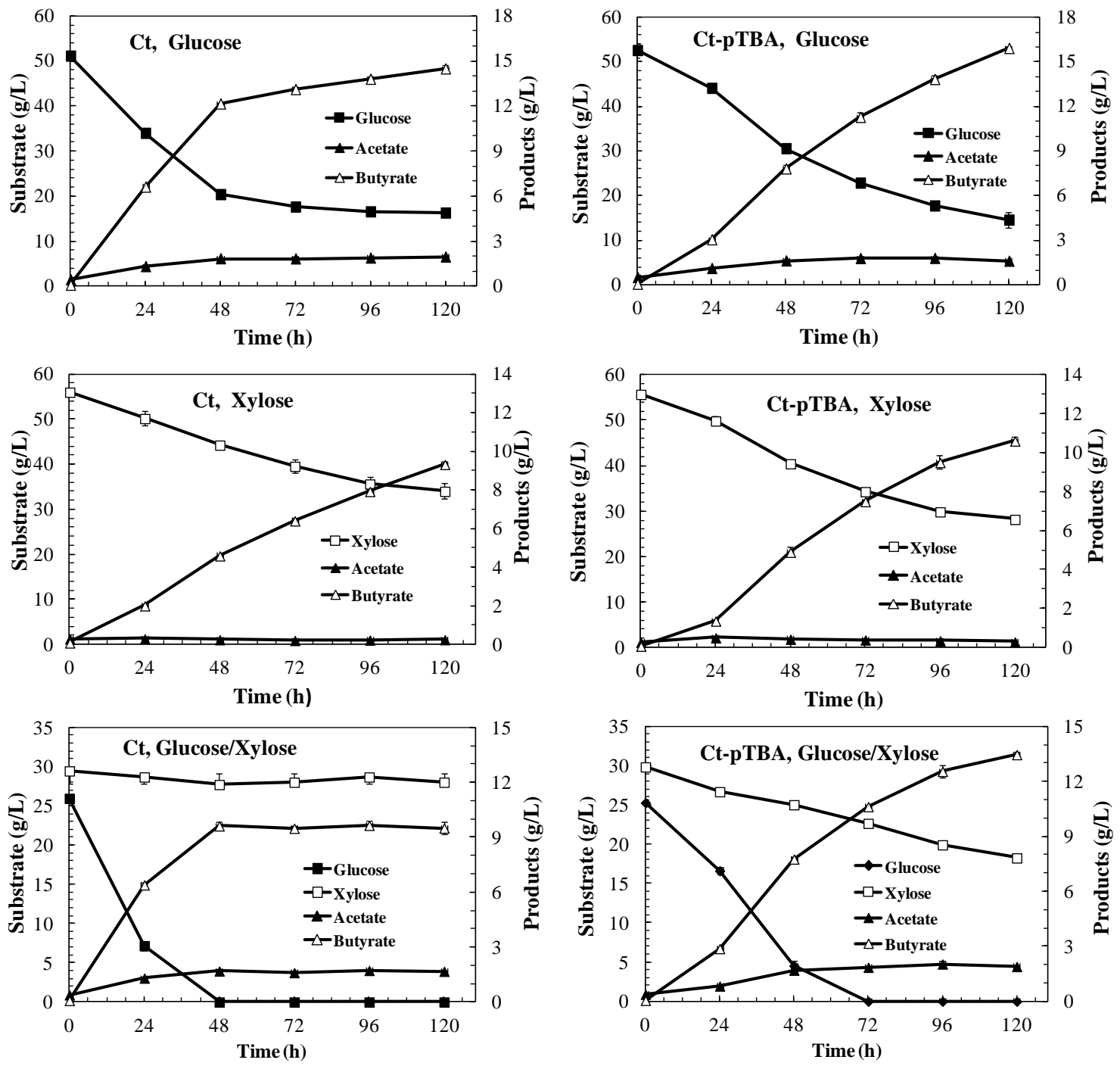

\section{Figure 1}


A

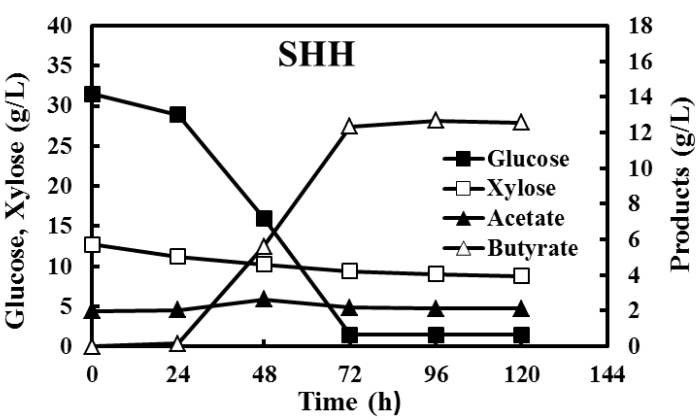

B

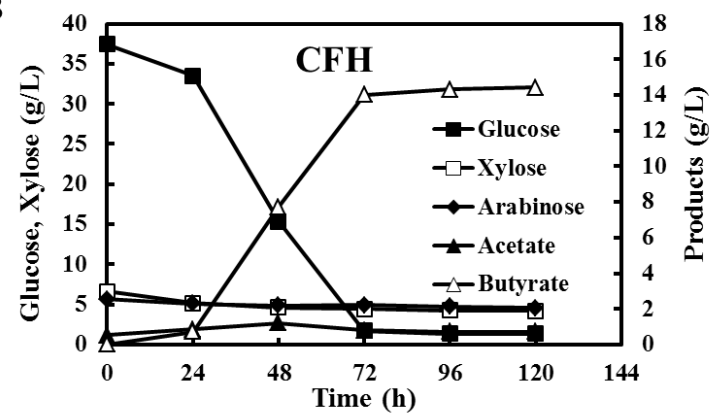

C

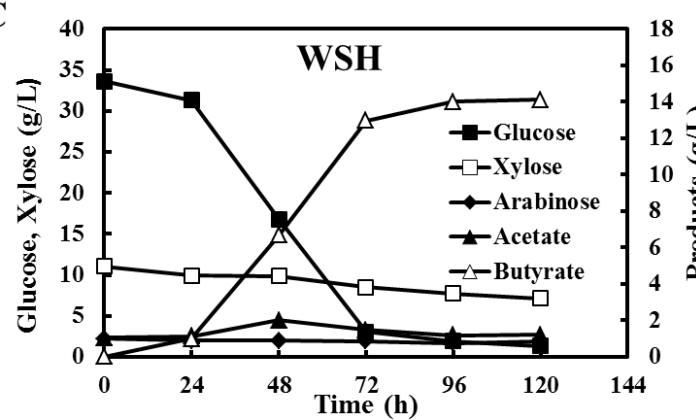

D

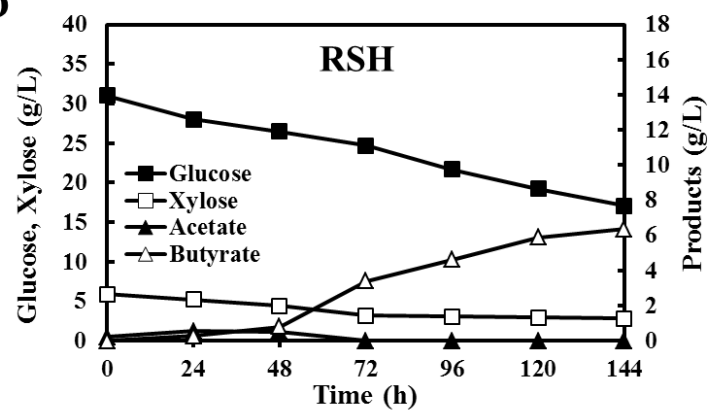

E

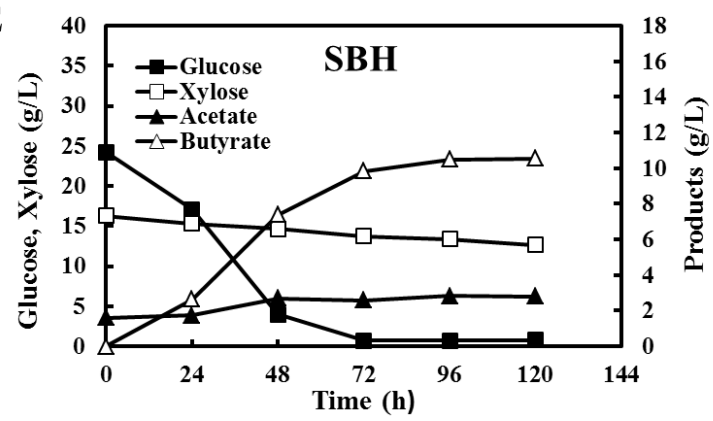

F

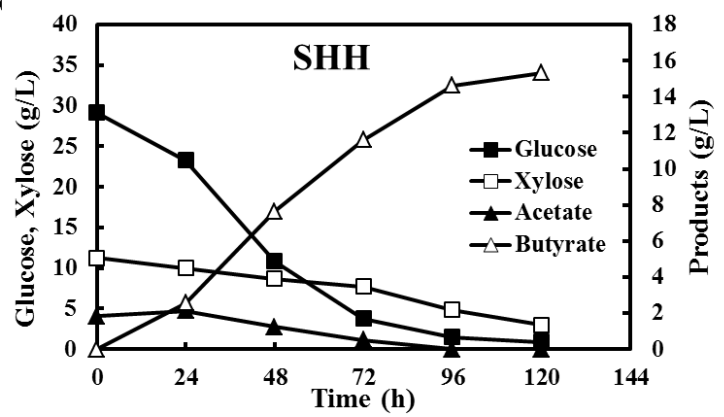

G

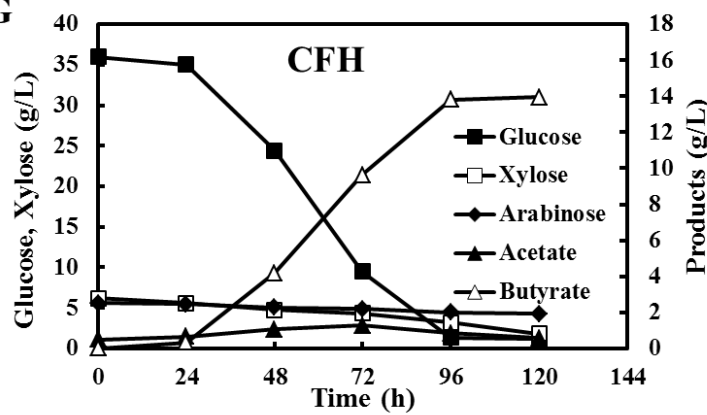

H
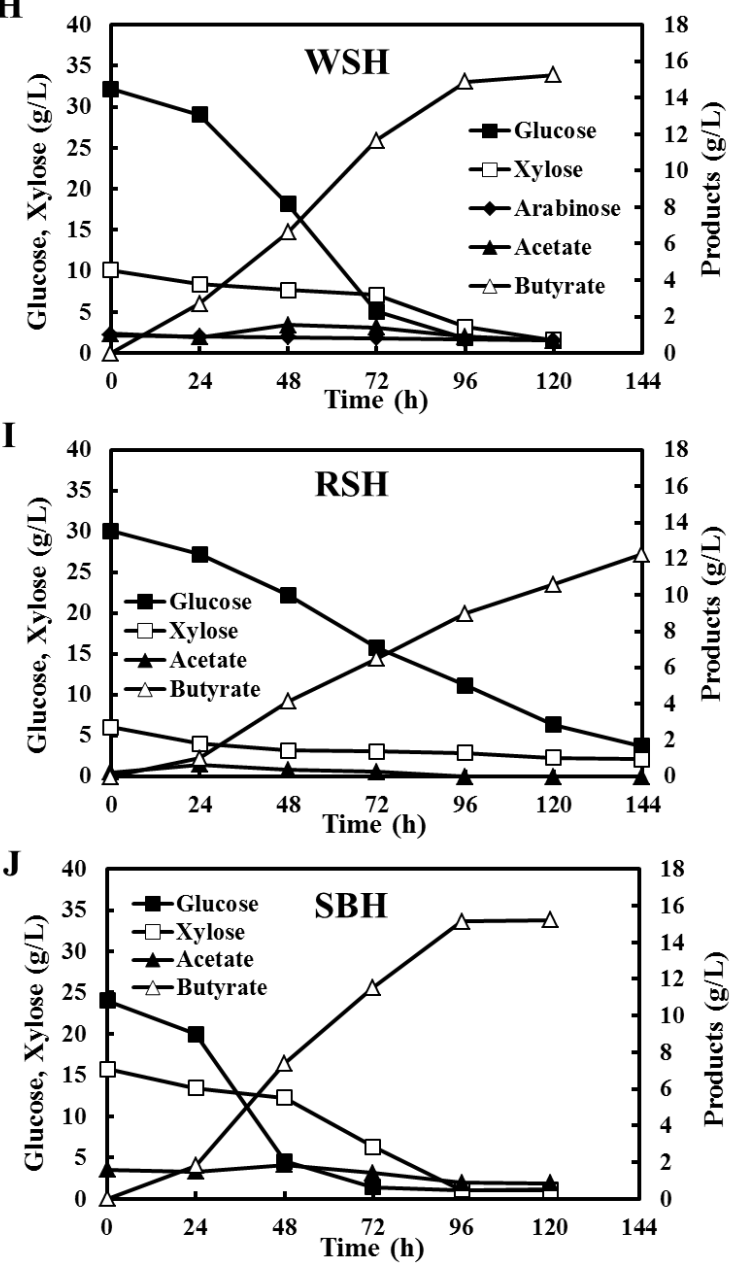

Figure 2 

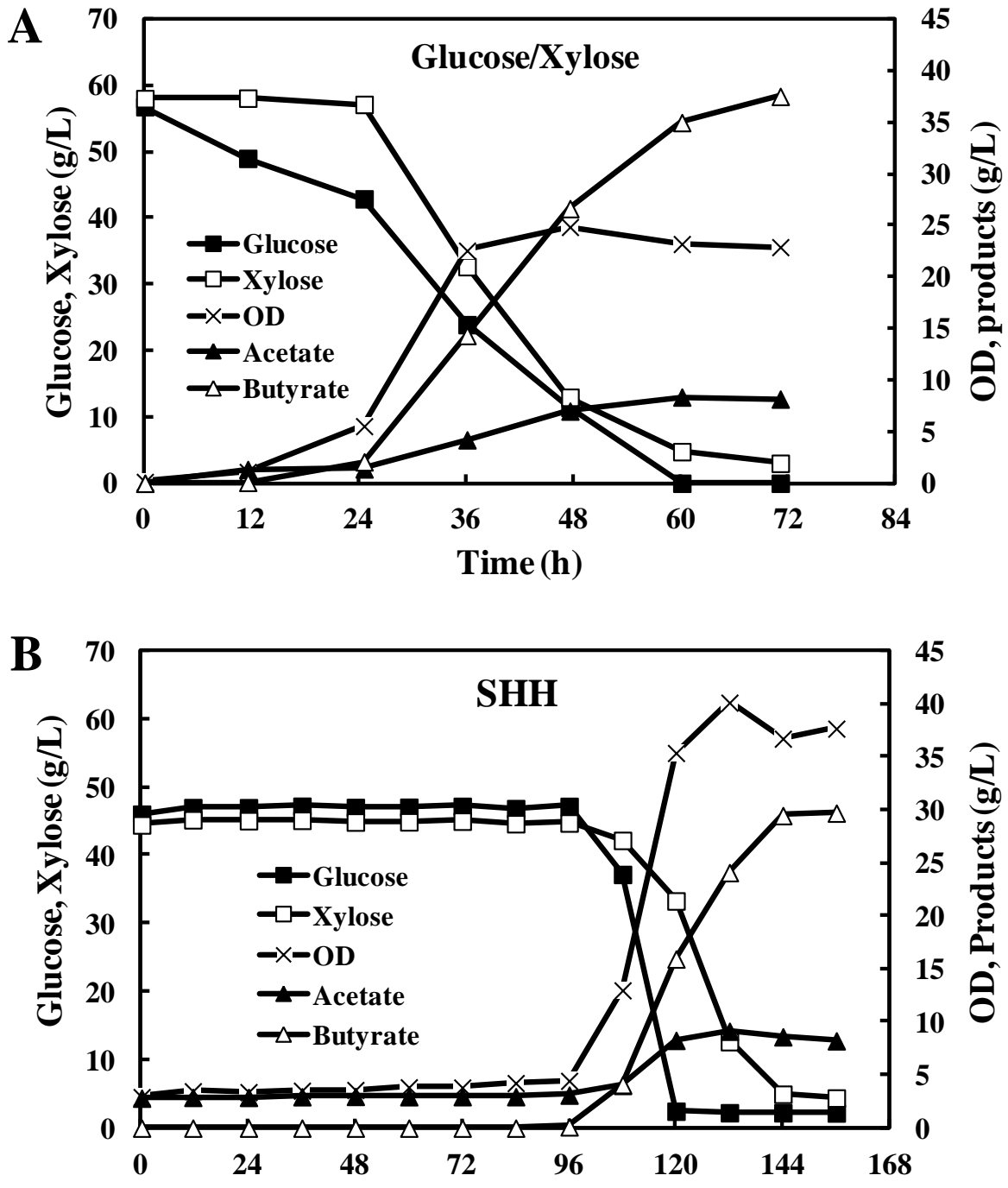

Time (h)

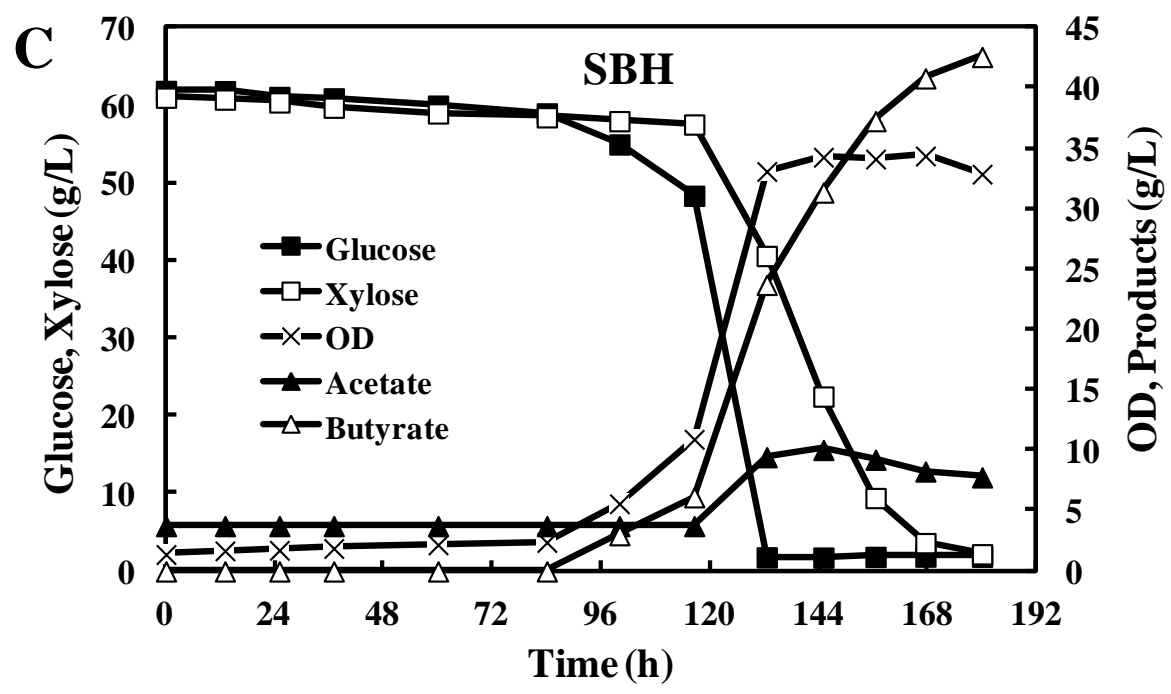

Figure 3 


\section{Graphical Abstract}

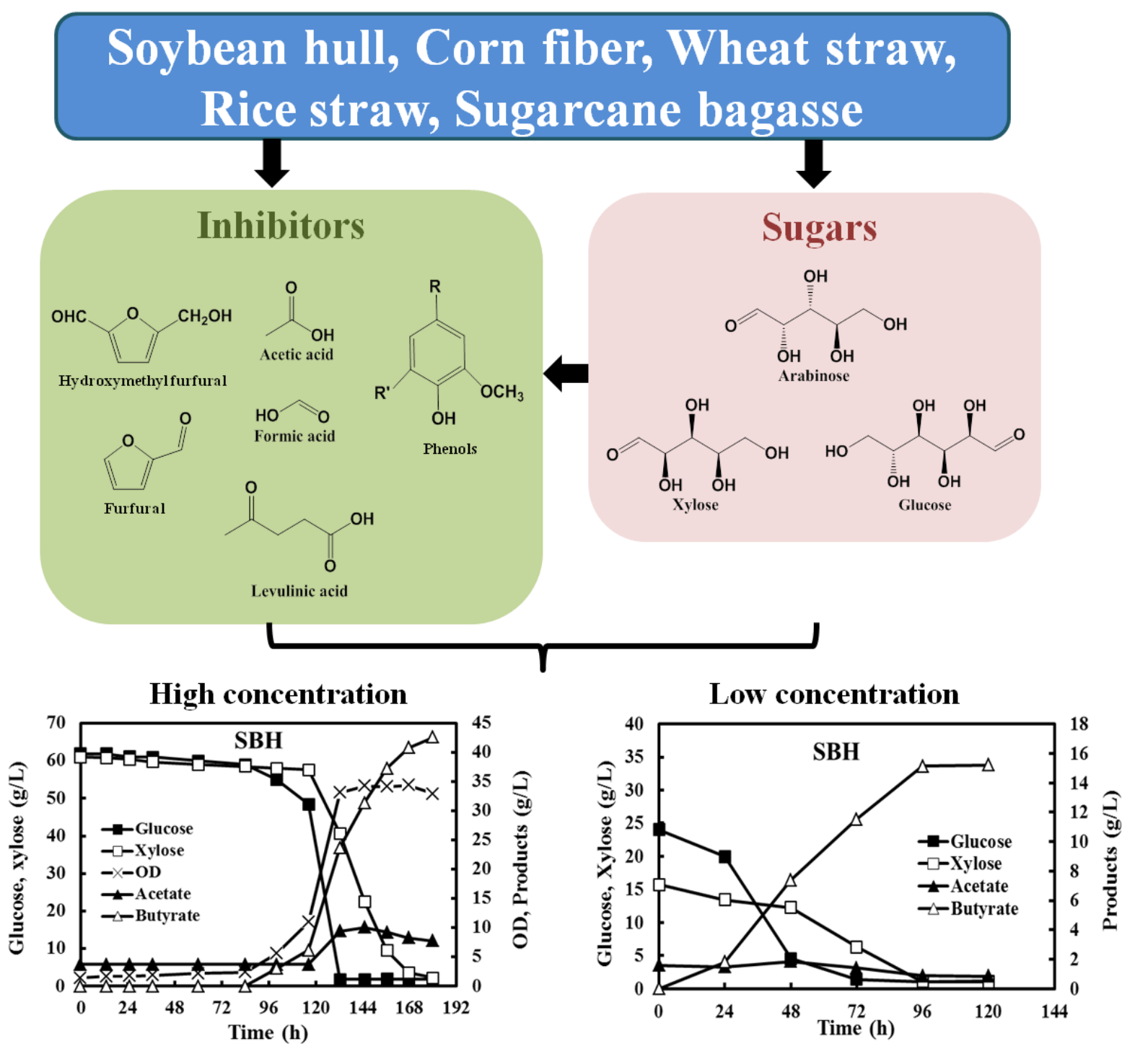

